\title{
A SINERGIA INSTITUCIONAL E A INDIVISIBILIDADE DE DIREITOS NA REALIDADE EUROPÉIA - A EXPERIÊNCIA DO ESTADO TURCO
}

\author{
THE INSTITUTIONAL SYNERGY AND THE RIGHTS INDIVISIBILITY ON THE \\ EUROPEAN REALITY - THE EXPERIENCE OF THE TURKISH STATE
}

\author{
Luís Felipe Bicalho ${ }^{1}$
}

\section{Resumo}

No presente estudo, apresenta-se o principio da indivisibilidade dos direitos a partir do marco teórico de Delmas-Marty e verifica-se sua aplicabilidade na estrutura institucional européia Corte Européia de Direitos Humanos e União Européia. Por fim, destaca-se o Estado Turco e sua tentativa de adesão ao bloco econômico europeu.

Palavras - chaves: Direitos Humanos; Direitos Econômicos; indivisibilidade dos direitos, Turquia.

\section{INTRODUÇÃO}

O estudo proposto busca analisar um tema que, no atual contexto da Internacionalização do Direito, apresenta fundamental importância: os efeitos da atuação das instituições internacionais no ambiente mundializado. Surge como inquietação intelectual, constituindo-se a hipótese contestável, a verificação da proximidade da relação entre instituições afetas a questões dos Direitos Humanos e instituições reguladoras das estruturas econômicas internacionais.

A abordagem dos Sistemas Regionais de Proteção dos Direitos do Homem, em especial do Sistema Europeu, e a análise paralela da estrutura formada pela União Européia (UE) constituem-se como modelos e objetos do estudo. Nesse sentido, a partir do recorte proposto, examina-se a atuação da Corte Européia de Direitos Humanos (CEDH) e a influência que esta exerce nas decisões do bloco econômico europeu.

Nesse sentido, fundamentado-se a partir do marco teórico de Delmas Marty e das considerações da autora quanto ao principio da indivisibilidade dos direitos, busca-se esclarecer a sinergia existente nesse amálgama de instituições européias. Em um segundo

1 Graduação em Direito pelo Centro Universitário de Brasília (2009). Atualmente é Mestrando em Direito das Relações Internacionais pelo Centro Universitário de Brasília.Servidor Público do Tribunal de Justiça do Distrito Federal e Territórios TJDFT; Bolsista do Programa de Estágio para docência do Instituto CEUB de Pesquisa e Desenvolvimento ICPD; Integrante de Projetos de Pesquisa do UniCEUB a) Grupo de Pesquisa Internacionalização do Direito; b) Grupo de Pesquisa Estudos do Mercosul; Pesquisador atuante nas áreas de Direito Constitucional, Direitos Humanos, Direito Comunitário e Direito de Integração, Sistemas Comparados e Políticas Públicas. 
momento, empreende-se uma análise dogmática e jurisprudencial que, a despeito de apresentar discursos jurídicos distintos, pode elucidar o estudo quanto à aplicabilidade prática das conclusões teóricas. Nesse ponto, evidencia-se a recente experiência do Estado Turco e sua tentativa de adesão à UE.

\section{INDIVISIBILIDADE DOS DIREITOS NA REALIDADE INSTITUCIONAL EUROPÉIA}

Atualmente, verifica-se que o processo de Internacionalização do Direito alcançou proporções inéditas. Emerge-se uma nova agenda ditada pela expansão dos temas tratados pelo Direito Internacional. A proliferação de atores e organismos internacionais ${ }^{2}$ e a multiplicação de instrumentos jurídicos é um exemplo fático dessa nova realidade (BERMAN, 2005: p. 491).

Nesse aspecto, tem-se conferido crescente destaque às questões relacionadas à defesa dos Direitos Humanos, panorama intencionalmente construído a partir das atrocidades cometidas durante as Guerras Mundiais. É igualmente no contexto do pós-guerra que é criado o Conselho da Europa e elabora-se a Convenção Européia de Direitos Humanos. Assim, observa-se o advento dos Sistemas Regionais de Proteção dos Direitos Humanos e a multiplicação dos Tribunais Internacionais. Como exemplo, tem-se o Sistema Europeu de Proteção dos Direitos Humanos e a CEDH (MERRILLS e A.H., 2001: p. 11-12).

Em outro aspecto, há de se frisar que, nas últimas décadas, a humanidade viveu um avanço tecnológico e científico sem precedentes, contudo, tal prosperidade trouxe consigo dificuldades ainda não superadas. Antônio Augusto Cançado Trindade (2006: p. 109-110) afirma:

\footnotetext{
“[...] O crepúsculo deste século desvenda um panorama de progresso científico e tecnológico sem precedentes acompanhado de padecimentos humanos indescritíveis. Ao longo deste século de trágicas contradições, do divórcio entre a sabedoria e o conhecimento especializado, da antinomia entre o domínio das ciências e o descontrole dos impulsos humanos, das oscilações entre avanços e retrocessos, gradualmente se transformou a função do direito internacional, como instrumental jurídico já não só de regulação como sobretudo de libertação".
}

As mazelas sociais passaram a deflagrar efeitos em um contexto nunca antes dimensionado, em um âmbito que ultrapassa as fronteiras locais e regionais. As soluções devem ser proporcionais a esse inédito quadro desfavorável. Nesse aspecto, as instituições reguladoras do ambiente econômico internacional buscam adequar sua atuação à realidade

2 Segundo estimativas, em 2004 existiam mais de 6.000 Organizações Internacionais. CARREAU, Dominique. Droit International. $8^{\circ}$ ed. Paris: A. Pedone, 2004, p. 129. 
globalizada, a fim de contraporem as dificuldades verificadas, a exemplo do bloco da UE. Por este motivo, a importância do Direito Internacional se apresenta, atualmente, muito mais ligada a uma necessidade imediata de solução integrada de conflitos - das mais diversas causas - do que mero reflexo desse novo cenário de estreita integração em que o homem se insere. O advento dos Sistemas Regionais de Proteção dos Direitos Humanos e o destaque na atuação das instituições econômicas internacionais são importantes exemplos dessa realidade.

Sabe-se que a temática dos direitos humanos é um objeto complexo, resultante de um conjunto amplo de determinantes e causalidades que não podem ser analisadas a partir de uma visão fragmentada e redutora. Nesse aspecto, invariavelmente, o sistema de proteção dos direitos humanos articula-se com práticas políticas e econômicas, estreitamente conectadas com a atuação das instituições e dos governos nacionais. Essa consideração torna-se relevante face a um dos proeminentes aspectos da discussão atual dos direitos do homem, aquele que evidencia o confronto com a racionalidade própria do mundo econômico, permeado por preceitos liberais, diga-se, por vezes, anticoletivistas, e propugna a dissociação entre as esferas de direitos humanos e econômicos.

A crítica da dissociação subsidia-se no principio da indivisibilidade dos direitos, destacando a impossibilidade de separação entre as esferas jurídicas a partir da frágil concepção de uma diferença irredutível de natureza jurídica dos direitos. (DELMASMARTY, 2003: 45).

E, ainda que a discussão possa se concentrar no âmbito teórico, seus efeitos igualmente se verificam no contexto institucional europeu, o qual se forma a partir de dois conjuntos principais, ora mencionados, o Sistema Europeu de Proteção dos Direitos Humanos, com destaque para a atuação da CEDH, e o bloco econômico da UE. Inicialmente, a própria estruturação dessa realidade se concebe a partir da consideração, por parte dos Estados Nacionais, da importância do respeito aos direitos do homem, tendo em vista as condicionantes impostas para adesão no bloco econômico europeu. Nesse sentido:

\footnotetext{
Progressivamente, quase quarenta Estados europeus filiaram-se a esse sistema de proteção dos direitos do homem. Isto já é um considerável avanço histórico, mesmo levando-se em conta que o argumento econômico pode ter desempenhado algum papel nessa filiação, na medida em que a entrada à comunidade européia está, de fato, subordinada à certificação de respeito aos direitos do homem que se dá pela ratificação da CESDH e pelo reconhecimento do recurso individual (DELMASMARTY, 2003: 31).
}

Em um segundo momento, no âmbito jurisdicional, a CEDH igualmente tem enfrentado, ainda que reflexamente, tentativas de dissociação dos direitos. E, nesse aspecto, o Tribunal tem estendido sua atuação, em princípio limitada aos direitos civis e políticos, a fim 
de contestar a possibilidade da separação estanque. Constata-se a assertiva em passagem do caso AIREY v. IRELAND:

Whilst the Convention sets forth what are essentially civil and political rights, many of them have implications of a social or economic nature. The Court therefore considers, like the Commission, that the mere fact that an interpretation of the Convention may extend into the sphere of social and economic rights should not be a decisive factor against such an interpretation; there is no water-tight division separating that sphere from the field covered by the Convention ${ }^{3}$.

Desse modo, evidencia-se a indissociabilidade dos direitos humanos e dos direitos econômicos - esferas que não se contrapõem, não se excluem, mas se complementam, de tal modo que a inobservância de uma inviabiliza a consecução plena da outra. Nesse sentido, na lição de Delmas-Marty, os direitos do homem devem ser interpretados e aplicados como um conjunto coerente e indivisível, coerente porque indivisível (2003: p. 40).

Por conseguinte, a partir da verificação da incidência do principio da indivisibilidade, anula-se a possibilidade de uma sobreposição da atividade das instituições européias. Refutase a opção por uma lógica de aplicação disjuntiva entre os sistemas, a partir da consideração, pela UE, da praxe jurisprudencial e do discurso humanista proposto pelo Tribunal Europeu. E, desse modo, a construção da coerência conceitual e lógica, no âmbito de atuação das instituições, não permite restar condicionantes para a efetividade jurídica dos direitos humanos (COSTA et al, 2008: p. 57). O desenvolvimento econômico permanece como importante fim, mas sua possibilidade se estrutura essencialmente na constatação da defesa dos direitos humanos pelo Estado Nacional.

Em sentido contrário, assim não procedendo, tem-se a continuidade da denegação da tutela de importantes comandos constitucionais e a conseqüente inviabilização do desenvolvimento econômico (COSTA et al, 2008: p. 331). Nesse eventual quadro refratário, de generalizada dissociação entre a esfera de direitos humanos e econômicos, permite-se que a Lei fundamental não passe de uma Carta poética e política, sem qualquer juridicidade aplicável. Uma Constituição aparente (DALLARI, 1982). Como se verá, não é o caso da realidade Européia.

3 Caso AIREY v. IRELAND, outubro de 1979, Application no. 6289/73. 


\section{SISTEMAS E INSTITUIÇÕES DO CONTINENTE EUROPEU}

\subsection{O Sistema Europeu de Proteção dos Direitos Humanos}

O Sistema Europeu de Proteção dos Direitos Humanos tem como pilares o Conselho da Europa $^{4}$ e a Convenção Européia de Direitos Humanos (CESDH) ${ }^{5}$. Com o Protocolo n. ${ }^{\circ}$ 11, de 1998, a estrutura do Sistema modificou-se substancialmente. Estabeleceu-se a CEDH, com caráter permanente ${ }^{6}$, composta atualmente por 47 juízes, representando cada um dos Estados da Convenção e do Conselho (POSNER e YOO, 2004). A partir de então, permitiu-se que não só o Estado, mas também o indivíduo pleiteasse diretamente a responsabilidade internacional do Estado. ${ }^{7}$

O Sistema Europeu dispõe do Comitê de Ministros, principal órgão político do Conselho da Europa, com o intuito específico de supervisionar a execução dos julgamentos da $\mathrm{CEDH}^{8}$. O Comitê determina uma agenda de supervisão, em que figuram todas as demandas da Corte e os seus respectivos estágios de implementação - compliance. A atuação do Comitê permite que a efetividade do Sistema não fique subjugada ao bel-prazer das instituições dos Estados Nacionais. Após o exercício de suas funções e a verificação da completa implementação da decisão da Corte, o Comitê emite resolução dando por encerrada sua atuação naquele caso.

\subsection{A União Européia}

A UE se configura em um bloco composto por 27 Estados, com o intuito de promover a unidade política e econômica, bem como reduzir as desigualdades sociais da Europa. De inicio, à época de sua formação no período pós-guerra, constituiu-se com objetivos eminentemente econômicos, passando posteriormente a buscar outras finalidades.

O ingresso ao bloco se inicia com a candidatura do Estado interessado. A adesão está condicionada à implementação de algumas medidas, tais quais, um governo estável e democrático, instituições que assegurem o Estado de Direito e respeito aos direitos humanos.

4 Criado pelo Tratado de Londres, em 05 de maio de 1949

5 Convenção para a proteção dos Direitos do Homem e das liberdades fundamentais ou Convention de Sauvegarde des Droits de 1'Homme et des Libertés Fondamentales, assinada em Roma no dia 04 de novembro de 1950.

6 Nessa Corte permanente também se fundiu a Comissão Européia de Direitos humanos.

7. Convenção Européia de Direitos Humanos, Art. 34. (Petições Individuais): “O Tribunal pode receber petições de qualquer pessoa singular, organização não governamental ou grupo de particulares que se considere vítima de violação por qualquer Alta Parte Contratante dos direitos reconhecidos na Convenção ou nos seus protocolos. As Altas Partes Contratantes comprometem-se a não criar qualquer entrave ao exercício efetivo desse direito"

8 Disponível em: < http://www.coe.int/t/cm/humanRights_en.asp\#TopOfPage>

Acesso em: 14/09/2010.

Revista da Faculdade Mineira de Direito, v.12, n. 23, jan./jun. 2011 - ISSN 1808-9429. 
Assim, considerando a possibilidade de adesão ao bloco europeu, questiona-se quanto aos benefícios advindos desse ingresso.

Inicialmente, a liberdade na circulação de mercadorias, bens, serviços, capitais e pessoas, possibilidades que se efetivaram a partir do Tratado de Maastricht, facilitam o crescimento econômico dos Estados componentes do bloco europeu.

Um dos aspectos proeminentes, no que tange às possibilidades de desenvolvimento, é a ajuda financeira que o Bloco Europeu injeta no Estado membro. Como exemplo da grandiosidade do aporte econômico, para o período de 2007 a 2013, há previsão de gastos da ordem de 347 bilhões de euros em infra-estrutura, meio ambiente e capacitação profissional dos cidadãos das regiões menos favorecidos do bloco, ou seja, aquelas que possuam um PIB per capita inferior a $75 \%$ da média européia. Objetivamente, em comparação com outras potencias mundiais, a UE destaca-se como maior fomentadora pública do desenvolvimento:

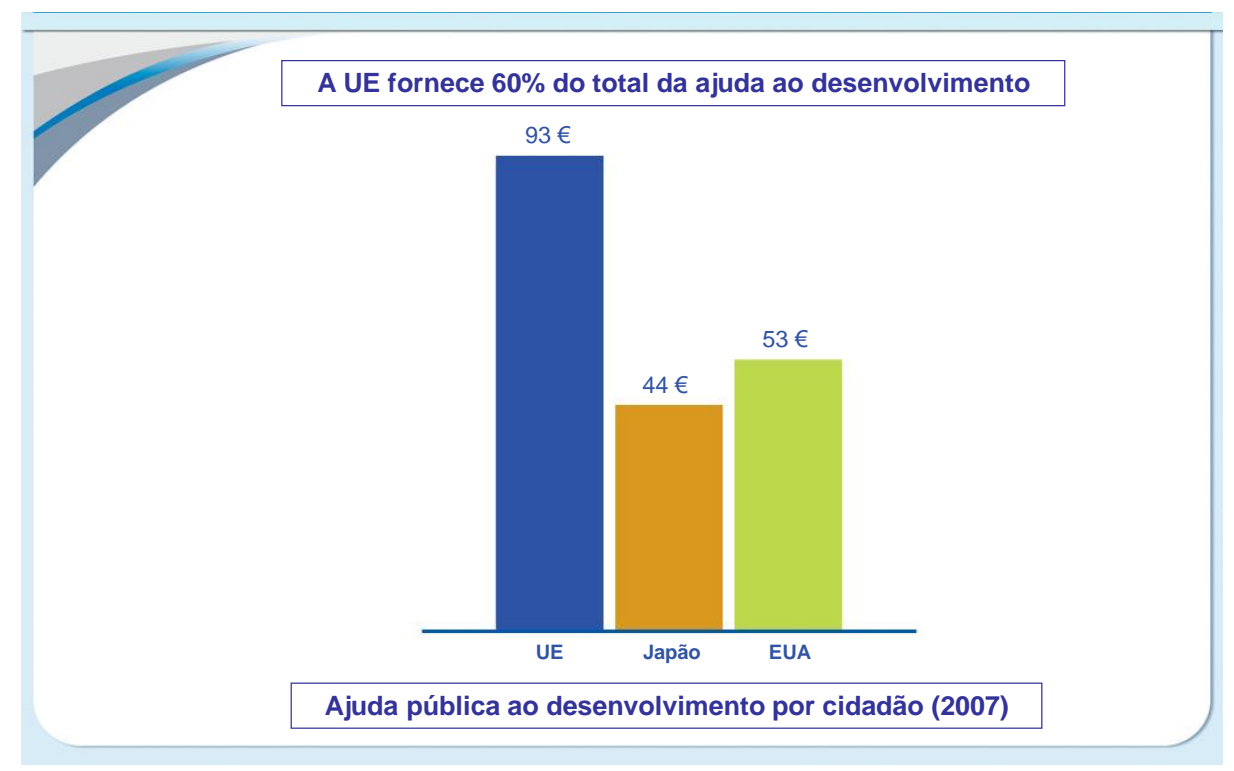

Figura I - média de ajuda pública para desenvolvimento por cidadão ${ }^{9}$

Essa programação de gastos faz parte dos objetivos de convergência, para os quais se aceita a existência de uma realidade européia com geometrias diferentes e que necessariamente deve se desenvolver considerando as distintas realidades econômicas e sociais, ainda que tal processo ocorra para cada Estado em diferentes velocidades.

Igualmente, ressalta-se que pertencer à zona do Euro é inegavelmente uma garantia de estabilidade econômica. Nesse aspecto, a atuação do Banco Central Europeu é imprescindível,

9 Informação disponível em: http://europa.eu/index_pt.htm. Acesso em 05/10/2010. 
destacando-se entre suas atribuições a fixação das taxas de juros, a manutenção dos índices de inflação, uniformização dos tributos e a gerência das reservas e divisas da UE.

Nesse sentido, apresenta-se gráfico demonstrativo da queda do índice médio de inflação dos Estados membros do Bloco Europeu que passaram a utilizar a moeda única:

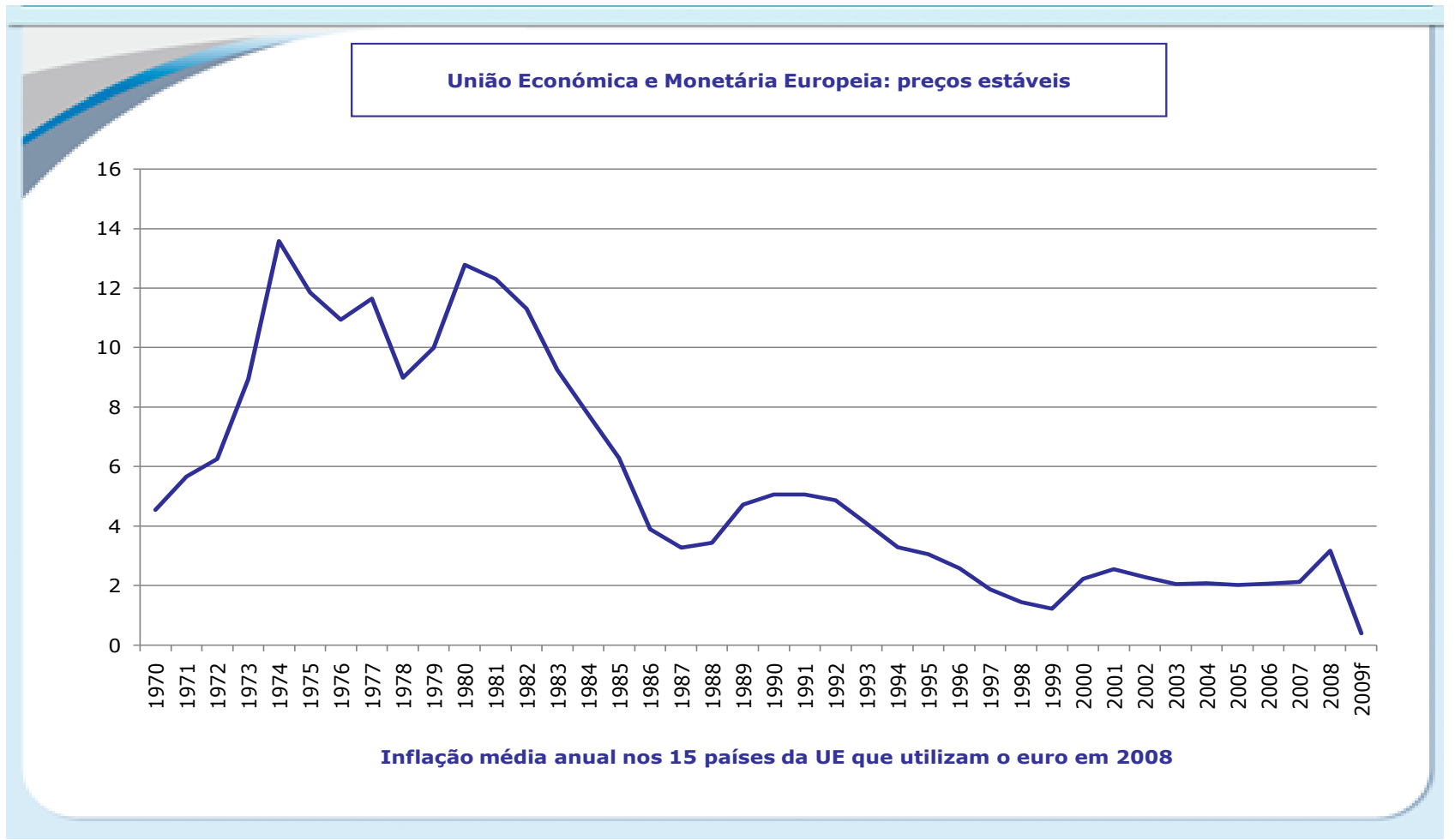

Figura II - índice médio de inflação dos Estados membros pertencentes à zona do Euro ${ }^{10}$

Destarte, permite-se construir solidez de mercado e das finanças públicas por meio de uma moeda estável, tal qual o Euro. E, acrescida da ajuda financeira do bloco, facilita-se o desenvolvimento do Estado e se criam condições facilitadoras para continuidade desse processo.

\section{A EXPERIÊNCIA TURCA: O CONFRONTO DA RACIONALIDADE ECONÔMICA E A DEFESA DOS DIREITOS HUMANOS}

Nos últimos anos, tem se observado a tentativa de ingresso de alguns Estados ${ }^{11}$ na UE, dentre os quais se destaca a Turquia. Após sua candidatura, em outubro de 2005, aceita a despeito das reservas declaradas de importantes membros do bloco, como França e Alemanha, a Turquia iniciou as negociações e tentativas de adequação aos parâmetros condicionantes 
para adesão ${ }^{12}$. Contudo, o avanço no processo se mostra dificultoso. Não considerando outros importantes fatores - a religião muçulmana predominante, o enorme contingente populacional, as dificuldades econômicas ${ }^{13}$ - destaca-se como forte elemento para oposição ao ingresso da Turquia a sistemática violação aos Direitos Humanos que se verifica no país, em especial contra a minoria curda. A Turquia faz parte do grupo de Estados que assinaram e ratificaram a CESDH. Todavia, a continuidade de suas condenações pela CEDH vem sendo um entrave para a sua aceitação no bloco da UE.

Primeiramente, lembra-se que a CEDH não é um órgão da UE, mas componente da estrutura do Conselho da Europa. Entretanto, cumpre ressaltar que a influência de uma estrutura sobre a outra é inevitável, haja vista a UE ser composta, atualmente, de 27 Estados que igualmente são signatários da Convenção Européia de Direitos Humanos, ou seja, membros da CEDH e do Conselho da Europa.

Em 2007, constatou-se no relatório anual do Conselho da Europa que quatro Estados Rússia, Turquia, Romênia, Ucrânia - respondiam por aproximadamente 55\% das demandas pendentes de apreciação pela $\mathrm{CEDH}^{14}$. As mais distintas espécies de violação dos direitos humanos - desrespeito ao devido processo legal, uso abusivo da força, tortura, eliminação étnica. Em 2008, coletou-se dados semelhantes àqueles verificados no relatório anual anterior. Novamente, Rússia, Turquia, Romênia e Ucrânia respondiam pela grande parte dos casos pendentes da Corte, aproximadamente $57 \%{ }^{15}$. Por sua vez, o relatório anual de 2009 constatou um decréscimo do valor relativo em relação à totalidade de demandas. Contudo, os mesmos Estados respondiam por aproximadamente 55,7 \% das demandas ${ }^{16}$. Em 2010, no último relatório publicado, verificou-se novo aumento para os mesmos Estados, passando a 55,9\% do total de demandas pendentes na Corte ${ }^{17}$.

Ademais, verificou-se que nos últimos quatro anos a maioria de julgamentos realizados pela Corte relacionava-se ao Estado Turco. Nos anos de 2007, 2008, 2009 e 2010 foram submetidos ao crivo da $\mathrm{CEDH}$, respectivamente, 331, 264, 356 e 278 casos em que a Turquia figurava como violadora da CESDH. Não sendo suficiente, ainda se verifica que a Turquia também segue à frente no que tange ao descumprimento das decisões emanadas pela CEDH.

12 Informação disponível em: <http://portalexame.abril.com.br/economia/noticias/mundo/cameron-aborrecidolentidao-adesao-turquia-ue-582014.html>. Acesso: 14/09/2010.

13 Informação disponível em:

< http://europa.eu/abc/keyfigures/candidatecountries/index_pt.htm>. Acesso em: 14/09/2010.

14 Annual Report, 2007, European Court of Human Rights.

15 Annual Report, 2008, European Court of Human Rights.

16 Annual Report, 2009, European Court of Human Rights.

17 Annual Report, 2010, European Court of Human Rights. 
Tendo em vista a situação, a UE tem pressionado o Estado Turco para que acelere o processo de mudanças e busque uma atuação diametralmente oposta àquela exposta nos relatórios anuais da $\mathrm{CEDH}$. Nesse aspecto, não se trata da difusão de um modelo único, não se verifica imposições ideológicas. De fato, propugna-se a adequação das instituições a partir de uma proposta de harmonização dos sistemas de direito, admitindo-se certo relativismo, sem, contudo, esvaziar o núcleo de princípios fundadores comuns.

Por conseguinte, passa-se da concepção de uma universalidade mental para uma universalidade real, na medida em que, fundamentando-se na vontade de reconhecer os direitos comuns a todos os seres humanos, deflagra-se, intencionalmente, efeitos na esfera econômica dos Estados Nacionais (DELMAS-MARTY, 2003: p. 19-20).

E, na criação das condições ideais para a proteção dos direitos humanos, a atuação do Estado, imperiosamente, transita pela necessidade de elaboração de um ordenamento pátrio adequado, ainda que essa codificação deva se proceder em um ambiente internacionalizado e normativamente fragmentado. Assim, em resposta, o Estado Turco aprovou, em setembro de 2010, após votação popular, mudanças substanciais na Constituição Nacional, em especial, no que tange a ampliação dos direitos individuais e no fortalecimento do controle civil sobre o exército $^{18}$.

Todavia, não basta a Constituição propugnar a defesa dos direitos humanos, destacando poeticamente sua importância. A respeito da realidade européia, destaca DelmasMarty que, inicialmente, a certificação de respeito aos direitos do homem se dá pela ratificação da CESDH e pelo reconhecimento do recurso individual. Contudo, a constatação não se resume à abordagem normativa. Ao que parece, e este é o novo enfrentamento do Estado Turco, o ponto nevrálgico resta-se na efetividade:

É preciso ainda anotar que se trate de uma condição necessária mas não suficiente, como testemunham as lamentações da Turquia, que, condenada por inúmeras vezes pela Corte Européia dos Direitos do Homem em casos de torturas particularmente graves, viu recusado seu pedido de entrada na União (2003:31).

Esse preceito de efetividade tem importância central na atividade contenciosa da CEDH, sendo justificativa corrente para responsabilização internacional dos Estados. Inevitavelmente, o dispositivo amplia a complexidade do sistema jurídico, na medida em que implica em um direcionamento especifico para a produção normativa por parte do legislador nacional europeu, em especial dos Estados candidatos ao bloco econômico.

18 Informação disponível em: <http://www.estadao.com.br/noticias/internacional,ue-pede-a-turquia-maisreformas-para-ingresso-no-bloco,609157,0.htm>. Acesso:14/09/2010

Revista da Faculdade Mineira de Direito, v.12, n. 23, jan./jun. 2011 - ISSN 1808-9429. 
A incidência dos efeitos se verifica, essencialmente, na realidade dos jurisdicionados, ora receptores das novas disposições normativas advindas da reestruturação dos ordenamentos pátrios, ora agentes passivos na esfera de atuação das instituições internacionais, a exemplo da própria UE. Agora, sob o olhar atento da comunidade européia, espera-se que a nova Constituição da Turquia estabeleça um novo paradigma para o Estado, que esteja em consonância com as exigências da UE e, evidentemente, com o Sistema Europeu de Proteção dos Direitos Humanos.

\section{CONCLUSÃO}

No que tange aos Sistemas Regionais de Proteção dos Direitos Humanos, a nova abordagem do conceito de responsabilidade internacional é pressuposto para que as obrigações internacionais entre os Estados não se resumam a letra morta, perdendo completamente sua força jurídica vinculante. Desse modo, a criação dos órgãos jurisdicionais com caráter supranacional é uma importante alternativa para a proteção dos direitos dos jurisdicionados.

Desconsiderar o princípio da responsabilidade internacional equivaleria a reconhecer que os Estados não seriam obrigados a cumprir as obrigações reciprocamente assumidas - a negação da própria ordem jurídica internacional e a consequiente inefetividade do arcabouço jurídico mínimo do individuo. Contudo, incorrer-se-ia na mesma negação da ordem internacional se a estreita ligação existente entre a agenda dos direitos humanos e dos direitos econômicos fosse desconsiderada. Por esta razão, a análise do sistema europeu implica na necessidade de uma compreensão ampliada, na qual se observe a atuação da CEDH, bem como da UE.

Nesse sentido, constata-se que as instituições do continente europeu apresentam satisfatória sinergia na busca pela efetividade do Sistema Europeu de Proteção aos Direitos Humanos. Como exemplo, tem-se a influência que a CEDH exerce sobre a União Européia, em especial quanto à análise do preenchimento de requisitos para adesão ao bloco econômico.

Não por outro motivo, define-se a relação como sinergia institucional, haja vista a diferença de alcance e propósito não impedir que a atividade de uma instituição influencie a outra. Pelo contrário, a simultaneidade de forças concorrentes é uma proeminente característica da experiência européia. Nesse aspecto, a dificuldade que se verifica para ingresso dos Estados candidatos à UE deve-se a constatações da Corte, expostas anualmente em seus relatórios, a respeito das inúmeras violações aos direitos humanos, bem como a alta taxa de noncompliance de suas decisões.

Revista da Faculdade Mineira de Direito, v.12, n. 23, jan./jun. 2011 - ISSN 1808-9429. 
Mensurar o impacto da sanção moral no ambiente internacionalizado seria inviável. Entretanto, haja vista a lacuna de coercibilidade jurisdicional, é evidente a importância que a medida possui para a defesa dos direitos humanos no âmbito do Sistema Europeu, como exemplo, tem-se a experiência turca e a sua respectiva dificuldade para aderir ao bloco da União Européia.

Desse modo, pode-se considerar a obstaculização no procedimento de entrada à União Européia como um elemento de enorme coercitividade para aqueles Estados que, porventura, possuam um histórico de violações aos direitos humanos e uma prática de desrespeito às decisões da $\mathrm{CEDH}$. E, se não se pode prontamente indicá-la como um mecanismo de enforcement da própria Corte, claramente visualiza-se os mesmos efeitos práticos se assim o fosse.

Conclui-se pela inevitável dialética entre os sistemas, corolário do principio da indivisibilidade dos direitos, ora demonstrado a partir do marco teórico de Delmas-Marty. A comunicabilidade entre as lógicas implica em um rearranjo das forças de controle estatais, de modo a estabelecer uma relação essencial para a elaboração de uma resposta jurídica condizente aos anseios e necessidades na esfera dos direitos humanos.

Assim, nos dizeres da Assembléia Parlamentar do Conselho da Europa, o desenvolvimento social deve caminhar paralelamente e que, a termo mais ou menos longo, a negligência dos direitos sociais freará o desenvolvimento econômico. A assertiva, após pouco tempo, mostra-se desatualizada: os efeitos da evidente indissociabilidade já se fazem presentes.

\begin{abstract}
This study introduces the principle of rights indivisibility from the theoretical mark of Delmas-Marty and describes its applicability on the European institutional structure European Court of Human Rights and the European Union. Furthermore, the study highlights the Turkish State and its attempt to adherence for the European Union.
\end{abstract}

Keywords: Human Rights; Economic Rights; rights indivisibility, Turkey.

\title{
REFERÊNCIAS
}

BERMAN, Paul Schiff. From International Law to Law and Globalization, Columbia Journal of Transnational Law, 2005.

CARREAU, Dominique. Droit International. $8^{\circ}$ ed. Paris: A. Pedone, 2004. 
DELMAS-MARTY, Mireille. Três Desafios para um Direito Mundial, Ed. Lúmen Júris, Rio de Janeiro, 2003.

DALlARI, Dalmo de Abreu. Constituição e Constituinte, Editora Saraiva, São Paulo, 1982.

MERRILLS, J.G; A. H. Robertson. Direitos Humanos na Europa: um estudo da convenção européia de direitos humanos. $1^{\mathrm{a}}$ ed. Lisboa: Instituto Piaget, 2004.

POSNER, Eric A., YOO, John C.; A Theory of International Adjudication; John M. Olin Law \& Economics Research Paper Series Working Paper n. ${ }^{\circ} .206$ and Public Law and Legal Theory Research Paper Series Research Paper n. ${ }^{\circ} 146,2004$.

STERIO, Milena. The Evolution of International Law. Cleveland State University, Cleveland - Marshall College of Law, research paper 08-150, 2008.

TRINDADE, Antônio Augusto Cançado. A humanização do direito internacional. Belo Horizonte: Editora Del Rey, ano 2006.

VARELLA, Marcelo Dias. A crescente complexidade do sistema jurídico internacional Alguns problemas de coerência sistêmica. Revista de Informação Legislativa, V. 167, p. 135-170, 2005.

COSTA, Alexandre Bernardino; SOUZA JÚNIOR, José Geraldo de; DELDUQUE, Maria Célia; OLIVEIRA, Mariana Siqueira de Carvalho; DALLARI, Sueli Galdolfi; Universidade de Brasília [organizadores]. O Direito achado na rua: Introdução crítica ao direito à saúde, Brasília, UnB, 2008. 